TRIBUTE

\title{
In remembrance of our colleague Evan Weissman: Scholar, community leader, mentor, and friend
}

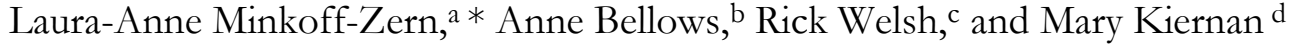 \\ Syracuse University
}

Submitted November 28, 2020 / Published online September 16, 2021

Citation: Minkoff-Zern, L.-A., Bellows, A., Welsh, R., \& Kiernan, M. (2021). In remembrance of our colleague Evan Weissman: Scholar, community leader, mentor, and friend. Journal of Agriculture, Food Systems, and Community Development, 10(4), 29-31. https://doi.org/10.5304/jafscd.2021.104.022

Copyright $@ 2021$ by the Authors. Published by the Lyson Center for Civic Agriculture and Food Systems. Open access under CC-BY license.

$I^{\prime}$ n the spring of 2020, we tragically lost our dear friend and colleague Evan Weissman, a food studies scholar and urban geographer, social justice advocate and activist, and renowned mentor and teacher. Evan was the first faculty member hired to start our intimate Food Studies Program, and an essential part of each of our individual careers and professional lives at Syracuse. It is difficult to impart the impact he had on our program, the discipline of food studies, and on us, as his coworkers and collaborators.

Evan's academic contributions, which focused on local food policy, community food systems, food system inequality, and urban agriculture, are beautifully reflected in this special issue. As can be seen here, the work he was engaged in has deep roots, which extend across topics and disciplines and continue to grow in his absence. His impact on the fields of food justice and sustainable agricultural and regional planning will endure, due to the ways he connected radical social theory and community-based practice.

As a faculty member, colleague, and advisor, he modeled thoughtful and purposeful scholar-activist research for his students and colleagues. He was an actively engaged member of the Syracuse food justice community on campus and off; a founding member of Syracuse Grows, a grassroots network that cultivates food justice through advocacy, education, and resources in support of urban food production; and

a* Corresponding author: Laura-Anne Minkoff-Zern, Associate Professor of Food Studies, Syracuse University; $\underline{\operatorname{lminkoff@syr.edu~}}$

b Anne Bellows, Professor of Food Studies, Syracuse University; acbellow@syr.edu

c Rick Welsh, Professor of Food Studies, Syracuse University; jrwelsh@syr.edu

d Mary Kiernan, Associate Teaching Professor of Nutrition and Food Studies, Syracuse University; mpkierna@syr.edu 
a founding member of the Syracuse-Onondaga Food Systems Alliance (SOFSA), a multisector coalition of stakeholders from across the food system in Onondaga County.

His scholastic projects were not simply academic endeavors; they were deeply personal projects, which built upon his lifelong connections and relationships in his hometown of Syracuse, New York. Days before his passing, Evan won the prestigious Syracuse University Lender Center Faculty Research Award, which is dedicated to progressive, socially inclusive, and interdisciplinary projects promoting university-community relations. The Lender Center leadership reports that Evan's proposal to promote food justice in Syracuse through collaborative work with the emerging SOFSA was unparalleled by competing proposals. Working with Evan's colleagues in Food Studies and Geography, Lender has supported the proposal's realization, to identify best practices for including social justice in food policy councils based on examples around the country. The project builds upon a five-year, community-based participatory effort of food system planning in Central New York ${ }^{1}$ to expand community capacity to address long-term public health, economic, and environmental impacts of the CNY food system and concurrently to offer direct student engagement in building and supporting diverse participation in SOFSA.

Following Evan's life-long commitment to social and racial justice, this project was designed to conduct this analysis from a critical justice lens, and to take seriously the race- and class-based food inequalities in our region. Working closely with local food-based organizations, Evan's vision to address food insecurity and inequality were central to this work. The project continues, with faculty and students maintaining the goals he outlined, with his memory as a constant guide.

In yet another example of his innovative and collaborative spirit, Evan teamed up with Dr. Harriet Brown in Magazine Studies and Dr. Anni Bellows in Food Studies to prepare and win a faculty grant to consider ways to expand interdisciplinary teaching of critical Fat Studies throughout the Syracuse campus. Today, the successful proposal is bringing together interested researchers from more than 12 disciplines to discuss and promote prominent authors in the very diverse directions that Fat Studies has taken. One objective is to identify common threads of interest and transdisciplinary development of the field.

Here at Syracuse University, Evan was well-known for his mentorship and special attention to students. He went above and beyond to support our students-always the professor to take a student out for a drink after a hard day, stay engaged in deep conversation, or let loose out on the dance floor after a day of conference-going. He offered his personal take on the food system and the world, connecting with students on an individual level. He listened to their experiences and offered mentorship from the specifics of professional endeavors to general musing on how to enjoy a good life. In recognition of this constant attention to students, he received numerous honors for his engaged community-based teaching, including the Syracuse University Excellence in Graduate Education Faculty Recognition Award, the Falk College Faculty of the Year Award for Teaching Excellence, the Syracuse University Faculty Sustainability Fellowship, a Teaching Recognition Award, as well as a Chancellor's Award for Public Engagement and Scholarship for his course, "Feeding the City."

On a personal level, Evan was in a unique position as an academic who also lived in his hometown. His pride in Syracuse, a rust-belt underdog city surrounded by classic agrarian imagery, shone through in the ways he made time to introduce newcomers, colleagues, and students alike to the community. He was the first one to recommend a great café or farm tour, always made sure everyone had explored our regional farmers market, and made it out to the most beautiful spots to swim and hike. His love for his city and desire to showcase its dynamic culture and livelihoods, was connected to the commitment he

\footnotetext{
${ }^{1}$ See http://www.foodplancny.org
} 
had to creating a more just and sustainable food system - to ensure that the region was developing and progressing to its full potential, to benefit all who live here.

We will never know what else Evan had to offer us as a scholar, a mentor, and an activist. What we can hold onto, though, are the impressions and influence he made in both his published work and teaching. His vision for justice in the food system and in society at large continues to live through his students, collaborations, and vision for a more just food system and society. 